\title{
Effects of prematurity, intrauterine growth status, and early dexamethasone treatment on postnatal bone mineralisation
}

\author{
S Kurl, K Heinonen, E Länsimies
}

\begin{abstract}
Aim-To examine the hypothesis that, apart from prematurity, intrauterine growth status (expressed as gestational age specific birth weight standard deviation scores), neonatal factors, and duration of dexamethasone treatment influence bone mineralisation in early infancy. Methods-In this prospective study, groups consisted of 15 preterm small for gestational age infants (SGA group) and 43 preterm appropriate for gestational age infants (AGA group). A reference group contained 17 term infants. Body size is known to affect bone mineral content (BMC), therefore postnatal bone mineralisation was measured when the study infants and controls had attained a similar body size. Bone mineral density (BMD) and BMC were determined by dual energy $x$ ray absorptiometer of the lumbar spine (L2-L4).

Results-Both preterm groups had significantly lower BMC and BMD than the weight matched term reference group, but no difference was found in BMC and BMD between preterm SGA and AGA infants. In stepwise regression analysis, bone area, duration of dexamethasone treatment, weight at examination, and weight gain per week were the most significant factors, explaining $54 \%$ of the variance of the BMC values.
\end{abstract}

Accepted 4 February

Table 1 Neonatal and growth data for the preterm appropriate for gestational age (AGA) and small for gestational age (SGA) groups

\begin{tabular}{llll}
\hline & $\begin{array}{l}\text { Preterm AGA } \\
\text { group }(n=43)\end{array}$ & $\begin{array}{l}\text { Preterm } S G A \\
\text { group }(n=15)\end{array}$ & p Value \\
\hline Boys/girls & $20 / 23$ & $6 / 9$ & - \\
Gestational age (weeks) & $30(4)$ & $31(2)$ & 0.355 \\
Birth weight (g) & $1620(740)$ & $1270(370)$ & 0.245 \\
Birth length (cm) & $40.0(5.2)$ & $40.0(3.8)$ & 0.461 \\
Dexamethasone treated & $16 / 43$ & $2 / 15$ & - \\
Duration of dexamethasone (days) & $15(7)$ & $10(4)$ & 0.067 \\
Chronological age (months) & $4.5(1.6)$ & $5.3(1.8)$ & 0.283 \\
Corrected age (months) & $3.0(2.6)$ & $3.4(1.4)$ & 0.269 \\
Weight at exam (g) & $5145(275)$ & $5246(293)$ & 0.192 \\
Height at exam (cm) & $56.0(2.4)$ & $56.8(2.0)$ & 0.248 \\
\hline
\end{tabular}

Data presented as mean (SD).

Table 2 Pertinent data of dexamethasone and non-dexamethasone groups

\begin{tabular}{llll}
\hline & $\begin{array}{l}\text { Dexamethasone } \\
\text { group }(n=18)\end{array}$ & $\begin{array}{l}\text { Non-dexamethasone } \\
\text { group }(n=40)\end{array}$ & p Value \\
\hline Respirator treated (n) & 18 & 21 & - \\
Respirator (days) & $25(15)$ & $2(5)$ & 0.000 \\
Extra oxygen (n) & 17 & 21 & - \\
Extra oxygen (days) & $34(22)$ & $8(12)$ & 0.000 \\
Weight at exam (g) & $5061(167)$ & $5221(307)$ & 0.039 \\
Height at exam (cm) & $55.5(2.5)$ & $56.3(2.1)$ & 0.131 \\
\hline
\end{tabular}

Data presented as mean (SD).
Conclusion-In particular, weight at examination, prematurity, and possibly dexamethasone treatment, but not intrauterine growth status, affect postnatal bone mineralisation.

(Arch Dis Child Fetal Neonatal Ed 2000;83:F109-F111)

Keywords: preterm infants; intrauterine growth status; bone mineral density; bone mineral content; dual energy absorptiometry; dexamethasone

Metabolic bone disease, characterised by decreased mineralisation of osteoid tissue, is a recognised complication in very low birth weight premature infants. Although preterm and term small for gestational age (SGA) infants have lower bone mineral content (BMC) at birth than infants of appropriate size for gestational age (AGA), ${ }^{1-6}$ the joint effects of prematurity and intrauterine growth retardation on postnatal bone mineralisation are controversial. ${ }^{7}$ Moreover, diseases associated with prematurity and their treatment may also affect BMC values. This is particularly true for dexamethasone treatment of chronic lung disease (bronchopulmonary dysplasia).$^{8-10}$

Previous data show that body size affects BMC. ${ }^{11}{ }^{12}$ We therefore decided to measure postnatal bone mineralisation when our preterm infants and controls had attained similar body size. In this study, we examined the hypothesis that, apart from prematurity, intrauterine growth status (expressed as gestational age specific birth weight standard deviation scores), neonatal factors, and duration of dexamethasone treatment influence bone mineralisation in early infancy.

\section{Patients and methods}

This prospective study consisted of 58 preterm infants: 15 preterm SGA infants and 43 preterm AGA infants. A reference group consisted of 17 term infants. Table 1 shows neonatal and growth data for the study infants. Eighteen infants received dexamethasone treatment for chronic lung disease; table 2 gives the pertinent clinical data. At birth, the infants were classified as SGA on the basis of gestational age specific birth weight standard deviation scores. ${ }^{13}$ The normal range for gestational age specific birth weight standard deviation scores is -2 to $+2 \mathrm{SD}$, and the infants below -2SD formed the SGA group. Gestational age specific birth weight was -2.8 (0.5) SD units (mean (1) SD) in the SGA group and -0.3 (1.1) SD units in AGA preterm infants. All infants were born at 
Kuopio University Hospital, Kuopio, Finland between November 1995 and September 1998. We excluded infants whose mothers had any clinical conditions known to affect calcium metabolism, such as diabetes, or parathyroid, bone, renal, and gastrointestinal disorders. None of the infants had congenital malformations, chromosomal abnormalities, or intrauterine infections. Informed parental consent was obtained for all study infants, and the study was approved by the ethics committee of Kuopio University Hospital.

After birth, preterm study infants of gestational age $\leqslant 33$ weeks $(n=35)$ received a recommended amount of 100-105 $\mathrm{mg}$ of calcium $/ 100 \mathrm{kcal}(418 \mathrm{~kJ})$ and $60-70 \mathrm{mg}$ of phosphorus $/ 100 \mathrm{kcal}^{14}{ }^{14}$ This consisted of calcium 50-55 mg/100 kcal and phosphorus $20-25 \mathrm{mg} / 100 \mathrm{kcal}$ from banked human milk and supplementation with calcium 45-50 $\mathrm{mg} / 100 \mathrm{kcal}$ (as calcium carbonate) and phosphorus $40-45 \mathrm{mg} / 100 \mathrm{kcal}$ (as sodium diphosphate). To avoid solubility problems, calcium and phosphate were given separately in three divided doses a day in the middle of milk feeds by syringe through a nasogastric tube. This supplementation, together with vitamin A 1000 IU/day, vitamin D 400 IU/day, and vitamin C $2 \mathrm{mg} /$ day, was started soon after birth and continued until the weight was $2.5 \mathrm{~kg}$ or until discharge if it occurred earlier. Infants born at $>33$ weeks $(n=23)$ received only vitamin D $400 \mathrm{IU} /$ day. In hospital, all preterm study infants received banked human milk fortified with a special formula containing hydrolysed whey protein to provide $2.4-3.0 \mathrm{~g}$ of protein $/ \mathrm{kg} /$ day and a daily energy intake of $135-140 \mathrm{kcal} / \mathrm{kg} /$ day until they reached $2.5 \mathrm{~kg}$. After discharge from hospital, the diets of all the infants were routinely supplemented with vitamin D $400 \mathrm{IU} /$ day. At the time of examination, 27 out of $58(46 \%)$ preterm (six SGA and 21 AGA) infants were being breast fed. Weight and height gain per week were calculated until the day of examination to assess the rate of growth. Weight matched full term controls $(n=17)$ were breast fed until examination.

We measured postnatal bone mineralisation in the study infants when their mean weight was $5.2(0.3) \mathrm{kg}$ in the SGA group, $5.1(0.3) \mathrm{kg}$ in the AGA group, and $5.1(0.3) \mathrm{kg}$ in the reference group. Bone mineral density (BMD) and BMC of the lumbar spine (L2-L4) were measured by dual energy $x$ ray absorptiometry (DXA) using a Lunar DPX densitometer (Lunar Radiation Corporation, Madison, Wisconsin, USA) with software version 3.8. The lumbar vertebrae L2 to L4 were chosen for

Table 3 Lumbar bone mineral density (BMD), bone mineral content (BMC) and bone area data for the preterm small for gestational age (SGA) and appropriate for gestational age $(A G A)$ groups and term controls

\begin{tabular}{|c|c|c|c|c|c|c|}
\hline & \multicolumn{2}{|l|}{ Preterm groups } & \multirow[b]{2}{*}{$\begin{array}{l}\text { Term controls } \\
A G A(n=17)\end{array}$} & \multirow{2}{*}{$\begin{array}{l}\text { p Value } \\
\text { SGA v } \\
\text { Term }\end{array}$} & \multirow{2}{*}{$\begin{array}{l}p \text { Value } \\
\text { AGA v } \\
\text { Term }\end{array}$} & \multirow{2}{*}{$\begin{array}{l}p \text { Value } \\
S G A \text { v } \\
A G A\end{array}$} \\
\hline & $S G A(n=15)$ & $\begin{array}{l}A G A \\
(n=43)\end{array}$ & & & & \\
\hline $\mathrm{BMD}\left(\mathrm{g} / \mathrm{cm}^{2}\right)$ & $0.19(0.05)$ & $0.17(0.04)$ & $0.30(0.07)$ & 0.000 & 0.000 & 0.093 \\
\hline $\mathrm{BMC}(\mathrm{g})$ & $1.35(0.34)$ & $1.24(0.34)$ & $2.03(0.50)$ & 0.001 & 0.000 & 0.223 \\
\hline Bone area $(\mathrm{cm})$ & $7.01(0.64)$ & $7.47(1.21)$ & $6.94(0.87)$ & 0.345 & 0.024 & 0.075 \\
\hline
\end{tabular}

Data presented as mean (SD). measurement because previous data from adults indicate that steroid induced bone loss is most pronounced in trabecular-rich regions such as the vertebral bodies. ${ }^{1516}$ Trabecular bone is also more sensitive to mineral changes than cortical bone. ${ }^{17}$ Scans were performed by a trained nurse. DXA expressed BMD in $\mathrm{g} / \mathrm{cm}^{2}$ and BMC in $\mathrm{g}$. All scans were performed with the child in a supine position and without sedation. The children were directly observed at all times by the person performing the scan. The scanning procedure was interrupted if any movement artefact was noted, and a repeat scan was performed when the child was pacified.

\section{STATISTICAL ANALYSIS}

Statistical analyses were performed using Statistical Package for Social Sciences (SPSS) for Windows 6.0. The non-parametric MannWhitney test was used to determine differences between AGA and SGA groups and between preterm and the reference groups.

To identify the factors that would affect BMC values in the preterm study infants, partial correlation coefficients were calculated between BMC and other variables while controlling for the effects of age, height, and weight at the time of examination. Forward stepwise multiple regression analysis was then carried out with BMC as the dependent variable. All continuous variables were converted into natural logarithms to linearise their relation with BMC (including BMC). Bone area, weight at examination, height at examination, gestational age specific birth weight standard deviation scores (indicating intrauterine growth status at birth), gestational age, duration of dexamethasone treatment, and weight and height gain per week were entered into the analysis as independent variables to discover the most significant factors explaining the variance in BMC values.

\section{Results}

Both preterm SGA and AGA groups had significantly lower lumbar BMC and BMD than the term reference group, but there were no significant differences in lumbar BMC, $\mathrm{BMD}$ and bone area between preterm SGA and AGA infants (table 3). Even when dexamethasone treated infants were excluded, lumbar BMC and BMD were similar in the preterm SGA (BMC 1.36 (0.37); BMD 0.19 (0.04)) and AGA (BMC 1.28 (0.27); BMD $0.17(0.03)$ ) groups ( $\mathrm{p}$ values 0.622 and 0.266 respectively).

When the effects of age, height, and weight at the time of examination were controlled, BMC correlated with gestational age $(r=0.2691$; $\mathrm{p}=0.047)$, bone area $(r=0.3439 ; \mathrm{p}=0.010)$, duration of respirator treatment $(r=-0.3091$; $\mathrm{p}=0.025)$, and duration of dexamethasone treatment $(r=-0.2840 ; \mathrm{p}=0.036)$, but not with either the gestational age specific birth weight standard deviation scores or the duration of breast milk feeding. In forward stepwise regression analysis performed for preterm infants (table 4), bone area, duration of 
Table 4 Forward stepwise multiple regression analysis of factors influencing Ln bone mineral content (BMC) in preterm infants

\begin{tabular}{lrll}
\hline Variable & Coefficient & $p$ & $R^{2}$ \\
\hline Ln Bone area + & 0.893 & 0.000 & 0.543 \\
Duration of dexamethasone use + & -0.015 & 0.000 & \\
Ln Weight at exam + & 1.661 & 0.005 & \\
Ln Weight gain per week & -1.836 & 0.016 &
\end{tabular}

dexamethasone treatment, and weight at examination were the best variables, explaining 54\% of the variance of the BMC values.

\section{Discussion}

Interpretation of BMC measurements by DXA in preterm infants is difficult because confounding variables such as gestational age, body size, and dietary intake should be considered. Several studies of different groups of infants (AGA and SGA infants, ${ }^{6}$ and infants of diabetic mothers ${ }^{19}$ ) have shown that whole body BMC correlates with gestational age and body length, and even more closely with body weight. Therefore we decided to compare postnatal bone mineralisation of preterm infants with that of weight matched full term controls. Under these circumstances, we found that both preterm SGA and AGA groups had significantly lower BMC values than the term reference group. We did not find lower BMC values in preterm SGA infants than in preterm AGA infants, as shown previously. ${ }^{7}$ It is unlikely that differences in feeding influenced our results, because the feeding regimen was similar in both preterm study groups.

The preterm infants receiving dexamethasone treatment for chronic lung disease were particularly at risk of decreased bone mineralisation, according to our data. Similarly, in a previous study, ${ }^{8}$ preterm infants treated with dexamethasone for a considerably longer mean period of 37 days had lower radial bone mineral accretion than controls at six months corrected age, while two other studies ${ }^{9}{ }^{10}$ failed to show differences in forearm BMC values between dexamethasone treated preterm infants with bronchopulmonary dysplasia and controls. Several factors may explain the dexamethasone effects observed in our study. Firstly, dexamethasone may have a direct negative effect on bone metabolism. ${ }^{18}$ Secondly, infants treated with dexamethasone, who obviously had more respiratory morbidity (as shown by the need for longer periods of ventilation and supplemental oxygen), also had less weight and height gain per week and lower weight at examination than non-dexamethasone treated prematures. The results imply that low BMC values in dexamethasone treated infants may in fact be related not to dexamethasone treatment per se but to the lower weights of the infants at the time of examination. We suggest that the variance in BMC values may be related to the variations in the individual weights.

We conclude that prematurity, rather than intrauterine growth status, affects postnatal bone mineralisation. More information is needed on complex inter-relations between nutritional factors, early growth, and bone mineral content before the effects of dexamethasone on bone mineralisation can be assessed.

The authors thank Pirjo Halonen, M Sc, Kuopio University, for her statistical assistance. $\mathrm{S} \mathrm{K}$ is grateful to the Administration of Kuopio University Hospital, to Kuopio University Foundation, and to Helena Vuorenmies Foundation for financial assistance.

\section{Key messages}

- Prematurely born SGA and AGA infants have significantly lower BMC than weight matched term AGA infants

- The degree of prematurity and postnatal dexamethasone treatment affect bone mineralisation, which is not affected by intrauterine growth retardation

1 Chunga Vega F, Gomez de Tejada MJ, Gonzalez Hachero J, Perez Cano R, Coronel Rodriguez C. Low bone mineral density in small for gestational age infants: correlations with cord blood zinc concentrations. Arch Dis Child Fetal Neonatal Ed 1996;75:F126-9.

2 Namgung R, Tsang RC, Specker BL, Sierra RI, Ho ML. Reduced serum osteocalcin and 1,25-dihydroxyvitamin D concentrations and low bone mineral content in small for gestational age infants: evidence of decreased bone formation rates. F Pediatr 1993;122:269-75.

3 Pohlandt F, Mathers N. Bone mineral content of appropriate and light for gestational age preterm and term newborn infants. Acta Paediatr Scand 1989;78:835-9.

4 Petersen S, Gotfredsen A, Kudsen FU. Total body bone mineral in light-for-gestational age infants and appropriate-for-gestational-age infants. Acta Paediatr Scand 1989;78:347-50.

5 Chen JY, Ling UP, Chiang WL, Liu CB, Chanlai SP. Total body bone mineral content in small for gestational age, appropriate-for-gestational-age, large-for-gestational-age term infants and appropriate-for-gestational-age preterm infants. Chung Hua I Hsueh Tsa Chih (Taipei) 1995;56:109-14

6 Lapillonne A, Braillon P, Claris O, Chatelain PG, Delmas PD, Salle BL. Body composition in appropriate and in small for gestational age infants. Acta Paediatr 1997;86:196-200

7 Milton SD, Steichen JJ, Tsang RC. Decreased bone mineral content in small- for-gestational-age infants compared with appropriate-for-gestational-age infants: normal serum 25-hydroxy vitamin $\mathrm{D}$ and decreasing parathyroid hormone. Pediatrics 1983;71:383-8.

8 Weiler HA, Paes B, Shah JK, Atkinson SA. Longitudinal assessment of growth and bone mineral accretion in prematurely born infants treated for chronic lung disease with dexamethasone. Early Hum Dev 1997; 47:271-86.

9 Ryan S, Congdon PJ, Horsman A, James JR, Truscott J, Arthur R. Bone mineral content in bronchopulmonary dysplasia. Arch Dis Child 1987;62:889-94.

10 Greer FR, McCormick A. Bone mineral content and growth in very-low-birth-weight premature infants. Does bronchopulmonary dysplasia make a difference? Am $\mathcal{F}$ Dis Child 1987;141:179-83.

11 Koo WW, Walters J, Bush AJ, Chesney RW, Carlson SE. Dual-energy x-ray absorptiometry studies of bone mineral status in newborn infants. F Bone Miner Res 1996;11:9971002 .

12 Rubinacci A, Sirtori P, Moro G, Galli L, Minoli I, Tessari L. Is there an impact of birth weight and early life nutrition on bone mineral content in preterm born infants and children? Acta Paediatr 1993;82:711-13.

13 Pihkala J, Hakala T, Voutilainen P, Raivio K. New Finnish growth charts. Duodecim 1989;105:1540-6.

14 Committee on Nutrition of preterm infant, European Society of Pediatric gastroenterology and Nutrition. Nutrition and feeding of preterm infants. Acta Pediatr Scand and feeding of preterm

15 Amin S, LaValley MP, Simms RW, Felson DT. The role of vitamin D in corticosteroid-induced osteoporosis: a metavitamin D in corticosteroid-induced osteoporosis: a m
analytic approach. Arthritis Rheum 1999;42:1740-51.

16 Saag KG, Emkey R, Schnitzer TJ, et al. Alendronate for the prevention and treatment of glucocorticoid-induced osteoporosis. Glucocorticoid-Induced Osteoporosis Intervention Study Group. N Engl F Med 1998;339:292-9.

7 Seeman E, Wahner HW, Offord KP, Kumar R, Johnson WJ, Riggs BL. Differential effects of endocrine dysfunction on the axial and the appendicular skeleton. $\mathcal{F}$ Clin Invest 1982;69:1302-9.

18 Shrivastava A, Lyon A, McIntosh N. The effect of dexamethasone on growth and bone mineralisation in preterm infants with chronic lung disease. Early Hum Dev 1995;43:101-2.

19 Lapillonne A, Guerin S, Braillon P, Claris O, Delmas PD, Salle BL. Diabetes during pregnancy does not alter whole body bone mineral content in infants. $\mathcal{F}$ Clin Endocrinol Metab 1997;82:3993-7. 